\title{
Watch, Share or Create: The Influence of Personality Traits and User Motivation on TikTok Mobile Video Usage
}

https://doi.org/10.3991/ijim.v14i04.12429

\author{
Bahiyah Omar $^{(\bowtie)}$, Wang Dequan \\ University Sains Malaysia, Penang, Malaysia \\ bahiyah@usm.my
}

\begin{abstract}
Internet users are increasingly becoming self-publishing consumers. Applying the Uses and Gratifications (U\&G) perspective, this study investigated how people use TikTok in terms of consuming, participating and producing behaviors, and examined the role of personality traits and users' motivation as predictors to this integrated usage behavior. An online survey was conducted to recruit 385 TikTok users using online network sampling technique. Our findings suggest that it was users' motivations, not personality traits, that have significant influence on TikTok use. Results show that users' motivations - namely archiving, self-expression, social interaction and escapism - are significant predictors to TikTok usage behaviors but differ in levels and influence. This study contributes to both the theoretical and the empirical understanding of media use in a user-generated media (UGM) context.
\end{abstract}

Keywords - Mobile video, TikTok, Uses \& Gratifications (U\&G), User Generated Media (UGM), Personality Traits, Motivations, Social Networking Sites (SNS)

\section{Introduction}

Mobile videos have become mainstream and ubiquitous with the increasing availability of high-speed Internet. Studies of mobile video prototypes suggested that viewing episodes on mobile devices should be short [1] to sustain the attention of viewers. This discovery led to the introduction of TikTok, known as Douyin in China, in 2016 by a Beijing-based company-Bytedance [2]. It is a social networking app for creating and sharing videos that span only 15 seconds by which users can use a variety of filters, BGM (background Music) and lip-synching templates to communicate to the online community of viewers. Since its inception, TikTok is one of the emerging mobile video applications that has attracted millions of users worldwide. TikTok reached 150 million daily active users (500 million monthly active users) in June 2018 , and was the world's most downloaded app in the first quarter of 2018 [3], with an estimated 45.8 million downloads [4]. TikTok's attraction partly stems from its nature as one of the social 
media platforms; an Internet application that has the ideological and technological foundations of Web 2.0 [5] which allows for the creation and exchange of user-generated content. User-generated content (UGC) plus social media is an integrated form of communication that provides people with the opportunity to create content, share and establish their own network. It is common at present for hundreds of millions of internet users to be self-publishing consumers. Researchers [6]) argue that this phenomenon has blurred the distinction between consumers and producers, resulting in social networking sites (SNSs) being utilized by consumers for their own initiatives and motives.

TikTok is a manifestation of user generated media (UGM) as creating content is its backbone. In fact, UGM would not prosper without the content from users. It has also reshaped the market of video sharing whereby content is being created by a myriad of users instead of a limited number of media producers [7]. Some short videos become popular in a short period of time. This is often referred to as viral video phenomena, where certain videos become popular through the high frequency of sharing activities via email, social media sites, etc. Virality of a video is often seen as a measure of online success [8], and often impacted by the size of the fan base or the offline social capital [9]. The viral videos on TikTok attract thousands of comments and millions of views, likes and dislikes, thereby promoting further engagement. Hence, the use of UGM involves two important activities; creating the content and sharing the content online. Nevertheless, studies found that most people use media as mere lurkers, meaning that they are passive users who read, watch and browse only [10]. Takahashi, Fujimoto and N. Yamasaki [11] define lurkers as those "who do not post any messages in an online community" (p.1) but engage in consumption behavior [7]. Hence, the third aspect of UGM usage is consumption of media content. Shao [12] summarizes that the way people deal with UGM that involves consuming (i.e.: browse, watch, read, or view), participating (i.e.: like, add, share, post and comment) and producing (i.e.: create and publish personal content). Hence, media use at the advent of UGM also include multifaceted online activities.

Our goal is to examine how social media users use TikTok; a relatively new online application which is still not fully probed through research as yet. This study examines TikTok usage behavior by applying Shao's [12] framework which was developed on the existing research findings from $U \& G$ and other social-psychological literature. Advocating the idea of active audience, the theory guides the assessment of users' motivations of media use and access [13] and the understanding of social and psychological factors influencing media use[14] [15] [16]. Previous user-generated media (UGM) research examined the effects of personality traits (e.g.: [17] [18] [19] [20] [21]), and motivations (e.g.: [22] [23] [7]) on media usage behaviors. We draw from past research within $U \& G$ research framework and aim to investigate the influence of personality traits and users' motivations on three levels of TikTok use. They are consuming, participating and producing behaviors. 


\section{Theoretical Background and Hypothesis Development}

Central to Uses and Gratifications (U\&G) theory is the premise that the audiences are active, and their media use is goal directed and focused [24]. Audiences are motivated to use a certain medium to satisfy their needs from the other media types. The theory is useful to clarify people's choice of a particular media and to understand the fundamental needs that rouse people to utilize that media [24]. Earlier research has applied U\&G in many scenarios of traditional media use such as motives for television viewing [25]) and radio listening [26]) and its application has been widely extended to new media use such as Facebook [27] and Instagram [28]. Its wide application in research of various contexts is its greatest strength. U\&G has been lauded for its heuristic value in providing useful insights into the adoption of new media [29] and hence its application in understanding the use of TikTok as an emerging user generated media (UGM) is especially timely.

One of the assumptions of $U \& G$ is the socio-psychological origins of needs which lead to different pattern of media exposure [30]. Swanson [31] claimed that individuals are motivated by psychological, social and sociocultural influences to use mass media to accomplish some ends conceived as "gratifications". Much contemporary research concerning audience needs for media use have focused on individuals' motivations to meet their needs [23] and most often these studies compared the use of different media types according to different forms of motivations [32]. There are also studies that investigate the effects of users' motivation on media use in relation to other influential factors such as medium characteristics [22] and users' attributes [7] particularly for determining its unique contribution to media use. Meanwhile, uncovering the links between personality traits and media use, within $U \& G$ research domain, has been a recurring topic of study (e.g.: [33] [34]). The wide application of U\&G in media research has significantly contributed to the understanding of media use in the contemporary online environment. Nevertheless, the changing nature of how users use media in today's digital context is often ignored. Most studies conceptualize media use as the degree of media exposure [35] or habitual use of media in everyday life [36]. The advent of user generated media (UGM), hence, calls for the need to examine media use beyond exposure. The present study responds to this call by examining audience passive consumption of TikTok and their active involvement in interacting with the medium and other users (i.e: participation) as well as creating the content (i.e: production) for public view.

\subsection{Influence of personality traits on TikTok use}

U\&G theory underlines the role of individual differences (e.g., personality traits) in selecting media to gratify their needs. Personality traits represent generally enduring characteristics of individuals that show consistencies over their life and over a wide scope of circumstances [37] [38] which are more likely to reflect personal motives, needs, values, preferences and attributes [18]. Research has found that personality is an influential factor that predicts human behavior [39]. Among many typologies of personality traits, the Big-Five model (also called Five-Factor) was regarded as one of the 
most popular measure of personality [40]. This model suggested a combination of five specific factors namely neuroticism, extraversion, openness to experience, agreeableness and conscientiousness as personality traits. Empirical studies concerning user generated media (UGM) also discovered correlations between individual personality traits and UGM production and consumption (e.g.[41] [42] ). Correa, Hinsley and de Zuniga [15], for example, found that emotionally unstable people (i.e: neuroticism personality) used social media less while sociable people (i.e: extraversion personality) and those who enjoy new things (i.e: openness to experience personality) have high involvement in social media. In another study, Seidman [20] found that people characterized as courteous, flexible, good-natured, cooperative and tolerant (i.e: agreeableness personality) have the tendency to express one's real self on social media while those characterized as organized, efficient, and systematic (i.e: conscientiousness personality) are more likely to use social media to link and retain social connections. The literature suggests the influence of personality traits on social media use. Hence, this study proposes the following hypotheses:

- H1: Personality traits (neuroticism, extraversion, openness to experience, agreeableness, conscientiousness) are significantly associated with TikTok consuming behavior.

- H2: Personality traits (neuroticism, extraversion, openness to experience, agreeableness, conscientiousness) are significantly associated with TikTok participating behavior.

- H3: Personality traits (neuroticism, extraversion, openness to experience, agreeableness, conscientiousness) are positively related to TikTok producing behavior.

\subsection{Motivations for TikTok use}

Although U\&G has been typically applied to the study of mass media innovations, the theory provides a user-level view of mass media use [13]. This user-level approach seems to be particularly well suited for understanding the specific reasons that bring users to certain media such as TikTok. The application of U\&G has evolved in communication studies examining numerous types of new media including user generated media (UGM). These studies generally identified and profiled audience motivations for the use of the medium in question such as social networking sites [43], social media [44], Youtube [45] and Instagram [28]. Most often, the findings lead to the identification of different types of users' motivations and the understanding of motivation effects on media use. Chiang and Hsiao [45], for example, found that self-expression motive for the use of Youtube has significant effect on users' sharing behavior. For the context of TikTok use, we adopted Eunji and Jung-ah [28] social-psychological motivations for Instagram use. Although TikTok shares similar function with Youtube as a video producing tool, the latter is not originally created for usage on mobile devices and hence their utility functions are not the same. We found, however, that TikTok shares most similarities with Instagram as compared to other social media types as they are both social networking sites that allow access to short videos (in Instagram's case, also photos), provide comments and hearts for users to interact with the contents and other users, 
run messaging system for users to communicate with their networks, and also incorporate a mobile-friendly interface.

The five motivations are social interaction, archiving, self-expression, escapism and peeking.

Firstly, social interaction motive suggests the use of social media to fulfil needs to communicate and interact with others [46]. As a form of UGM, TikTok encourages users to send instant messages, comment and like the videos they watched; all of which facilitate social interactions.

Secondly, the emergence of the "archiving" motive on SNSs indicated that people take photos or videos and post them on social media to remember and retrospect special happenings and occasions in their lifetime [47]. It is about the need to be able to trace back their memories in their personal space and this can also be closely related to TikTok use.

Thirdly, many studies claim that users of UGM create their own content for selfexpression (e.g. [48] ) [49] [50]). Content creators take part in specific techniques to show themselves, draw in people's attention and cultivate supportive connections [51] [52] [53]. In the TikTok context, self-expression involves using videos to express about oneself or impress the audience with his/her talents.

Fourthly, escapism is the most common motivation for media use examined in past research since it denotes "pleasurable, fun, and enjoyable" experience with the media [54]. Whiting and Williams [44], found that people are motivated to escape or relieve themselves of day-to-day pressures through the use of social media. As a popular platform for joyful and fun activities like musical lip-syncing and meme, the need for escapism is expected to be associated with TikTok use.

Lastly, studies show that people are motivated to use social media to peek into other people's lives [55]. The advent of UGM has enabled exhibitionism and voyeurism [56] and people have developed pleasure from accessing private details [57] and peeking into the private lives of others [58]. Doster [56] in his qualitative study into the motive behind teen consumption of social media found normal voyeurism (peeking) was the most common reason for using social media. In the context of TikTok, users exhibit their lives or talents to others in the network who are expected to obtain personal, social and fantastical voyeuristic gratifications from its usage. Based on the literature, we propose the following hypotheses.

H4: Users' motivations (social interaction, archiving, self-expression, escapism, peeking) to use TikTok are significantly associated with TikTok consuming behaviors.

H5: Users' motivations (social interaction, archiving, self-expression, escapism, peeking) to use TikTok are significantly associated with TikTok participating behavior.

H6: Users' motivations (social interaction, archiving, self-expression, escapism, peeking) to use to TikTok are significantly associated with TikTok producing behaviors. 


\section{Methods}

\subsection{The sample}

Data was drawn from an online survey conducted in March 2019. The targeted population was TikTok users. To derive the sample, an online network sampling also known as a virtual snowball sampling was employed to recruit respondents from a large population of TikTok users. The use of this method is effective for descriptive and exploratory studies and for hard-to reach populations [59]. This method has been increasing applied in studies involving social media users as study samples (e.g.,[60] [55] [61]). The self-administered online survey was distributed through TikTok's messaging system and other social media platforms such as Wechat, Facebook, Whatsapp. Respondents were asked to share the survey through their social networks and the process continued until an adequate sample size was obtained. A sample of 385 TikTok users was finally achieved and the majority were from China $(87.5 \%)$ while only a small fraction hailed from other countries (12.5\%). Of the sample, $172(44.7 \%)$ were males and $213(55.3 \%)$ were females. Almost two-third of the respondents $(71.4 \%)$ were young adults aged between 20 and 34 years old.

\subsection{Variables}

Personality traits: In order to measure personality traits, we used a 25 -item scale adopted from the international personality item pool [62] [40]. Respondents were asked to indicate their agreement ( $1=$ strongly disagree, $5=$ strongly agree) with these statements. The first factor, neuroticism, contained five items such as "I get stressed out easily" and "I worry about things" which were combined to form an index of "neuroticism" ( $\mathrm{M}=3.19 ; \mathrm{SD}=.962 ; \alpha=.888)$. The second factor, extroversion, contained five items such as "I talk a lot to different people at parties" and "I feel comfortable around people", which were combined to form an index of "extroversion" $(\mathrm{M}=3.26 ; \mathrm{SD}=.854$; $\alpha=.849)$. Openness to experience is the third factor that contained five items, for example "I get excited by new ideas" and "I enjoy thinking about things". The 5-items measure of "openness to experience" was a reliable index $(\mathrm{M}=3.80 ; \mathrm{SD}=.730 ; \alpha=.852)$. The fourth factor, agreeableness, contained five items such as "I sympathize with others' feelings" and "I am concerned about others" (mean=3.92; SD=.719; alpha=.859). The fifth factor, conscientiousness, consisted of five items, for example "I carry out my plans" and "I pay attention to details". The five items were combined to form an index of "conscientiousness" $(\mathrm{M}=3.66 ; \mathrm{SD}=.767 ; \alpha=.880)$.

Users' motivations: Respondents were asked to express their agreement ( $1=$ strongly disagree; $5=$ strongly agree) on five motives to use TikTok. The motivations statement were adopted from L. Eunji and Jung-ah [28]. The first factor, social interaction, contained eight items such as "To interact with a number of people" and "To maintain a good relationship with others (for networking)" which were combined to form an index of "social interaction" $(\mathrm{M}=3.20 ; \mathrm{SD}=1.015 ; \alpha=.934)$. Archiving is the second motive and it contained six items, for example, "To save personal or others' interesting short 
videos", and "To compile a series of short videos". The six items were combined to form an index of "archiving" $(\mathrm{M}=3.15 ; \mathrm{SD}=1.147 ; \alpha=.948)$. For the third factor, selfexpression ( $M=2.88 ; \mathrm{SD}=1.165 ; \alpha=.933)$, respondents were asked to indicate their appraisal on five items, such as "To provide my update", and "To express my actual self (who I really am)". The fourth factor, escapism, contained five items, for example, "To escape from reality" and "To avoid loneliness". The five items were combined to form an index of "escapism" $(\mathrm{M}=3.10 ; \mathrm{SD}=1.012 ; \alpha=.872)$. The fifth factor, peeking, had four items such as "To peek on videos that people post" and "To stalk videos uploaded by my friends". The four items were combined to form an index of "peeking" $(\mathrm{M}=3.51$; $\mathrm{SD}=.931 ; \alpha=.814)$.

TikTok usage behaviors - Consuming, participating and producing: A measure of TikTok usage behaviors was developed based upon previous research from Shao [12] who claim that people manage UGM in three different ways: consuming, participating and producing. Respondents were asked to indicate his or her agreement ( $1=$ strongly disagree, $5=$ =strongly agree) with the statements of TikTok usage behaviors. The first factor, consuming, contained six items, such as "watch performance and imitation-type videos" and "watch lifestyle-type videos (such as travel, food, clothes, beauty)". The six items were combined to form an index of "TikTok consuming behavior" $(\mathrm{M}=3.56 ; \mathrm{SD}=.855 ; \alpha=.871)$. For the second factor, participating, respondents were asked to rate eight items, such as "comment on others' videos", 'like' others' videos" and "share others' videos on TikTok. The eight items were combined to form an index of "TikTok participating behavior" ( $\mathrm{M}=2.87 ; \mathrm{SD}=1.091 ; \alpha=.871)$. The third factor, producing, contained three items including "use lip-syncing songs to shoot videos" and "simply produce video without using TikTok's functions". The three items were combined to form an index of "TikTok producing behavior" $(\mathrm{M}=2.87$; $\mathrm{SD}=1.185 ; \alpha=.891)$.

Controlled variables - Demographic factors: In this study, we control the effects of some demographic characteristics that may have effects on TikTok use. We identified four demographic factors, deduced from past research, that were found to have significant influence on social media use. First is gender as past research has found gender difference in internet behaviors. A study by [63], for example, found that females with introversion and neuroticism personality tend to switch to social media for social services activities involving online chatting and discussion groups. Secondly, we include age in our analysis as well. Upadhyaya [27] found that young adolescents make the most of SNSs compared to the general population. Education level is the third factor that we sought. According to a demographic profile report [64], UGM users are more likely college educated people. Lastly, although country of origin is rarely considered in previous studies, there are studies that found people from different countries differ in their online behaviors. A study conducted by $\mathrm{Ng}$ [65], for example, found that Facebook users from Hong Kong and Japan had different motivations and behavior for using Facebook. Hence, country of origin is the fourth factor we noted in our analysis. These identified demographic factors were entered in the first block of regression model as controlled variables in the present study. 


\section{$4 \quad$ Analysis and Results}

\subsection{Preliminary correlation results}

We employed correlation test to determine how strongly pairs of variables in this study were related. Results indicate that most independent variables (personality traits and motivations to use TikTok) were positively and significantly related to dependent variables (consuming, participating and producing behavior), except for agreeableness which was not significantly correlated with participating and producing behaviors. Therefore, it was excluded from subsequent hierarchical regression analysis involving these two usage behaviors. Our initial exploration of the relationships among variables suggest that weak correlations $(\mathrm{r}<.3)$ exist for the relationships between personality traits and usage behaviors. Meanwhile, moderate $(r=.3$ to .5$)$ to strong $(r=.5$ to .1 .0$)$ correlations were found for the relationships between motivations and usage behaviors.

Table 1. Correlations between personality traits, motivations and TikTok usage behaviors

\begin{tabular}{|c|c|c|c|}
\hline \multirow[t]{2}{*}{ Variables } & Consuming behavior & Participating behavior & Producing behavior \\
\hline & $r(p)$ & $r(p)$ & $r(p)$ \\
\hline \multicolumn{4}{|l|}{ Personality traits } \\
\hline Neuroticism & $.273 * * *$ & $.169 * * *$ & $.189 * * *$ \\
\hline Extraversion & $.255^{* * * *}$ & $.393 * * *$ & $.312 * * *$ \\
\hline Openness to experiences & $.278 * * *$ & $.173 * * *$ & $.138 * * *$ \\
\hline Agreeableness & $.279 * * *$ & .096 & .066 \\
\hline Conscientiousness & $.329 * * *$ & $.292 * * *$ & $.227 * * *$ \\
\hline \multicolumn{4}{|l|}{ Motivations } \\
\hline Social interaction & $.560 * * *$ & $.689 * * *$ & $.604 * * *$ \\
\hline Archiving & $.526^{* * *}$ & $.685 * * *$ & $.747 * * *$ \\
\hline Self-expression & $.492 * * *$ & $.762 * * *$ & $.768 * * *$ \\
\hline Peeking & $.507 * * *$ & $.567 * * *$ & $.566^{* * *}$ \\
\hline Escapism & $.691 * * *$ & $.562 * * *$ & $.523 * * *$ \\
\hline
\end{tabular}

$\mathrm{N}=385, * \mathrm{p}<.05, * * \mathrm{p}<.01, * * *<.001$

\subsection{Test of hypotheses}

We later tested the hypotheses of the study using hierarchical regression analysis; a more robust statistical test which provides a framework for model comparison. In this analysis, demographic characteristics (i.e: gender, age group, education level, country of origin) were entered in the first block of the equation, followed by personality traits (neuroticism, extraversion, openness, agreeableness, conscientiousness) in the second block and motivations to use TikTok (social interaction, archiving, self-expression, escapism, peeking) in the third block. Testing the influence of a nested variables in a sequential process allows us to determine how much changes in variance $\left(\mathrm{R}^{2} \Delta\right)$ was explained by identified variables in each block while controlling the overlapping effects of other predictor variables. In this study, three separate hierarchical regression analyses 
were performed to compare three outcomes of usage behavior namely consuming, participating and producing.

Table 2 shows that demographic characteristics have no significant influence on all types of TikTok usage behavior except for the effect of country of origin on participating behavior $(\beta=.073, \mathrm{p}<.05)$. The result suggest that those originated from China have the tendency to comment, like and share videos when they use TikTok. One possible explanation to this phenomenon can be attributed to the Chinese culture of societycollectivism which is "a set of feelings, beliefs, behavioral intentions, and behaviors related to solidarity and concern for others" [66]. This culture encourages reciprocal interactions that promote appreciation and advice to motivate others. Hence, reciprocal gestures such as liking, sharing and commenting on videos uploaded by friends or strangers may contribute to this acquiescent and unanimous rule shared by China based users. This unspoken rule may explain the significant effect of country of origin on participating behavior on TikTok in the present study. However, we found that contribution of demographic factors in general is minimal and negligible to explain TikTok usage behavior.

Our findings also suggest that none of the personality traits was a significant predictor to TikTok usage behaviors ( $p>.05$ ). Hence, H1, H2, and H3 were rejected. Some significant findings, however, were found in the relationships between motivation to use TikTok and its usage behaviors. Firstly, we found that social interaction $(\beta=.210$, $\mathrm{p}<.01)$, archiving $(\beta=.193, \mathrm{p}<.05)$ and escapism $(\beta=.453, \mathrm{p}<.001)$ were significant predictors to TikTok consuming behavior, but self-expression and peeking were not. The results provided partial support for H4. Secondly, we found that all motivation factors significantly predicted TikTok participating behavior except for peeking ( $\beta$ $=.017, \mathrm{p}>.05)$. Thus, H5 was also partially supported. Thirdly, we found that archiving $(\beta=.380, p<.001)$ and self-expression $(\beta=.391, p<.001)$ were significant predictors to TikTok producing behavior, but no significant influence ( $p>.05)$ were found for social interaction, escapism and peeking motivations.

Table 2. Hierarchical regression analyses predicting TikTok usage behaviors

\begin{tabular}{|l|c|c|c|}
\hline \multicolumn{1}{|c|}{ Independent Variables } & Consuming behavior & $\begin{array}{c}\text { Participating } \\
\text { behavior }\end{array}$ & Producing behavior \\
\hline Block 1: Demographics & & & -.022 \\
\hline Gender (Female=1, Male=0) & .028 & -.048 & -.024 \\
\hline Age (adolescent=1, young adult=0) & -.006 & .073 & .078 \\
\hline Education (low=1, high=0) & -.043 & $.073 *$ & .041 \\
\hline Country (China=1, others=0) & .065 & .049 & .033 \\
\hline Adjusted R & .002 & & -.037 \\
\hline Block 2: Personality Traits & & -.046 & -.031 \\
\hline Neuroticism & .049 & .041 & -.064 \\
\hline Extroversion & -.059 & -.068 & - \\
\hline Openness & .009 & - & -.005 \\
\hline Agreeableness & .020 & .013 & .049 \\
\hline Conscientiousness & .071 & .147 & \\
\hline$\Delta \mathrm{R}^{2}$ & .148 & & \\
\hline Block 3: Users' Motivations & & & \\
\hline
\end{tabular}


Paper - Watch, Share or Create: The Influence of Personality Traits and User Motivation on TikTok...

\begin{tabular}{|l|c|c|c|}
\hline Social interaction & $.210 * *$ & $.159 * *$ & -.013 \\
\hline Archiving & $.193^{*}$ & $.148^{*}$ & $.380^{* * *}$ \\
\hline Self-expression &. .133 & $.422^{* * *}$ & $.391 * * *$ \\
\hline Peeking & .040 & .017 & .075 \\
\hline Escapism & $.453^{* * *}$ & $.124 *$ & .067 \\
\hline$\Delta R^{2}$ & .343 & .427 & .510 \\
\hline Total adjusted $R^{2}$ & .478 & .616 & .634 \\
\hline
\end{tabular}

Notes: Beta weights are from final regression equation with all blocks of variables in the model. Agreeableness were excluded from participating and producing analysis, as they are not significantly correlated. $\mathrm{N}=385$, $* \mathrm{p}<.05, * * \mathrm{p}<.01, * * * \mathrm{p}<.001$ (2-tailed)

Our findings suggest that users' motivations have much greater contribution to $R^{2}$ increment than personality traits in explaining TikTok usage behaviors. Users' motivations contributed to the increment in variance explained for producing behavior $\left(\Delta R^{2}=\right.$ $51 \%)$, followed by participating behavior $\left(\Delta R^{2}=43 \%\right)$, and consuming behavior $\left(\Delta R^{2}=34 \%\right)$. In terms of overall contributions of all factors in explaining TikTok usage behaviors, the results show that the factors contribute less to the total variance explained for consuming $\left(R^{2}=48 \%\right)$ as compared to participating $\left(R^{2}=62 \%\right)$ and producing $\left(R^{2}=63 \%\right)$ behaviors. The results suggest that people were more motivated to participate (i.e: like, share and comment) in other people's works and produce their own short videos than passively consume or watch the videos produced by others on this platform.

\section{$5 \quad$ Conclusion and Discussion}

This study builds its hypotheses based on Uses \& Gratification (U\&G) theory to examine the influence of personality traits and users' motivations on the use of TikTok. From this perspective, we empirically confirm findings of past research [67] [68] [32][47]) that found different types of motivation influence media usage. Specifically, we found that social media users consume or watch TikTok for escapism, social interaction and archiving purposes. Meanwhile, they participate in TikTok in order to express themselves, interact with others, and escape from day to day pressure. The motivation to produce TikTok videos, on the other hand, derive from the desire to fulfill their self-expression and archiving needs. Meanwhile, our findings also show that all the five personality traits were not significantly related to any TikTok usage behaviors. A possible explanation is that the relatively broad measure of personality traits based on the Big Five model may have failed to capture related characteristics that can explain TikTok usage behavior. It is important to note that the Big Five model has been criticized for its broadness (e.g. [69] [70]) and some scholars [71] have suggested the use of specific characteristics, such as shyness and curiosity, to better understand differences in people behavior in certain contexts. Despite these insignificant results, we cannot rule out the influence of personality traits on TikTok usage behavior. This is because our preliminary correlation results show existence of significant relationships between them (except for the relationships of agreeableness with participating and producing behaviors). Thus, this study sheds light on the significant contribution of users' motivation in predicting TikTok usage behavior, while the role of personality traits in explaining media use in UGM context has potential for investigation in future research. 
Besides, we echo past research (e.g: [72] [73] [23] ) that claim media use in the context of UGM is different from traditional media use and even Internet use in general because UGM involves content creation and audience participation. This study, thus, is different from past research within U\&G domain as these studies usually focus on a single outcome such as active media exposure [60]) and content creation [32]) as measures of media use. In fact, the integrated measure of media use is seldom found in past research [74] with exceptions of some studies (e.g.: [7] [75] [34]). Perhaps the most important contribution of this study is helping to quantify the measures of TikTok usage behaviors which later formed a reliable index (consuming: $\alpha=.871$; participating: $\alpha=.942$; producing: $\alpha=.891$ ) of the three UGM usages. The inclusion of the three levels of usage behavior provides some empirical evidences to better understand media use in UGM context and hence contributes to the U\&G literature.

While Shao [12] proposed specific motives for each usage behavior (i.e: entertainment and information for consuming, social interaction and community development for participating and self-actualization and self-expression for producing) in his framework, the present study found some overlapping motives across the three usage behaviors. Our findings suggest that archiving motive is a significant predictor to consuming, participating and producing behaviors. As a video app, it is not surprising to find that social media users saved and compiled videos at all levels; saving/compiling videos that they watched, saving/compiling videos that they liked/shared/commented on, as well as saving/compiling videos that they created themselves. Archiving appears to be the most important motivation for using TikTok in the present study. Peeking motive, however, was not significant at all levels. We can argue that the association did exist, as shown in significant correlation results, but peeking was not a significant predictor to TikTok use. Meanwhile, this study found that social interaction and escapism motives led to consuming and participating behavior. Social media users watched and participated in TikTok to relax and entertain. In addition, they use TikTok as a medium to communicate with others about the videos that they watched. Lastly, the motive of selfexpression was a significant predictor to participating and producing behaviors. This result suggests that social media users' active involvement in TikTok, from sharing other people's videos to creating own videos, was driven by the need to express themselves publicly.

As for managerial implications, it was found that the archiving motive explained why people watch, share and produce TikTok videos. On one hand, this result indicates the importance of facilitating and improving the utility functions for archiving videos on TikTok. We suggest some recommendations for improvement. First, background music incorporated in videos should be made easily traceable so that interested users can use the same music to save and compile videos on TikTok. Second, TikTok can push videos (such as anniversary reminders) posted in the past onto homepages of its users to help them recall their special occasions and thus encourage them to repost or reshare the videos in the network. Third, TikTok could enhance it's beautify function for shooting to make videos more vivid and realistic. This in turn encourage female users to shoot more videos and save them online for future sharing. On the other hand, we can form the assumption that users are more likely to regard TikTok as a video 
recording tool rather than a social media app. The small contributions of social interaction motive in explaining consuming and participating behavior in the present study seem to support this assumption. This particular finding is alarming because the success of a mobile short video depends on how many people watch and react on it; which are reflected by the number of 'views', 'likes, 'shares' and 'comment'. All of these measures can be accelerated through social interaction as viewing is usually increased when a mobile video receives a lot of likes and shares from social media users. Hence, the behaviors of users at the participating stage is crucial for TikTok to maintain loyalty among its users and continue to succeed amidst the mushrooming of social networking apps online. TikTok must optimize its interactive features to facilitate interactions between users and users, content creators and users, as well as users and the medium for its continuous success and sustainable development.

\section{$6 \quad$ Limitation and Recommendation for Future Research}

This study has several limitations.

First, the sample of the study was drawn from a non-probability sampling. Although the use of online network sampling technique suits the context of the present study and is effective in improving sample size, it has problems of sample representativeness. Fricker, Galesic, Tourangeau and Yan [76] associate the method with selection bias which can reduce the external validity of findings. Hence, the research results may lack generalizability that should be considered when interpreting the results. We encourage researchers to replicate this study on a more representative sample for further validation.

Second, the broad measure of Big Five model may contribute to the insignificant influence of personality traits in predicting TikTok usage behavior in the present study. We have two recommendations to deal with this; future research to look at more specific, subtle personality traits, such as shyness, curiosity and loneliness (see for examples, [77]) [71] [78]), and future research to compare users' motivations for different types of personality traits (see for examples, [79] [34]).

Third, this study is limited to exploring the influence of human factors on TikTok usage behaviors, while other influential factors such as medium characteristics, media environment and content appeals are ignored. Future researchers could consider these factors to gain a more comprehensive understanding of factors affecting users' behaviors within a UGM context.

\section{$7 \quad$ References}

[1] K. O. Hara, A. S. Mitchell, and A. Vorbau, "Consuming Video on Mobile Devices," in SIGCHI Conference on Human Factors in Computing Systems, 2007, pp. 857-866. https://doi.org/10.1145/1240624.1240754

[2] Ifeng.com, "Is Douyin a luxary product?," 2018. [Online]. Available: http://tech.ifeng.com/a/20180322/44916250 0.shtml. [Accessed: 01-Oct-2018]. 
[3] Xinhua, "Chinese video sharing app boasts $500 \mathrm{mln}$ monthly active users - Xinhua | English.news.cn," 2018. [Online]. Available: http://www.xinhuanet.com/english/201807/17/c_137330644.htm. [Accessed: 01-Oct-2018].

[4] A. Hartmans, "The most downloaded iPhone app in the world right now is one you've probably never heard of, Business Insider - Business Insider Singapore," 2018. [Online]. Available: https://www.businessinsider.sg/most-downloaded-iphone-apps-worldwide-tiktok-q1-2018-5/?r=US\&IR=T. [Accessed: 01-Oct-2018].

[5] A. Kaplan and M. Haenlein, "Users of the world, unite! The challenges and opportunities of Social Media," Bus. Horiz., vol. 53, pp. 59-68, 2005.

[6] M. Cooke and N. Buckley, "Web 2.0, Social Networks and The Future of Market Research," Int. J. Mark. Res., vol. 50, no. 2, pp. 267-292, 2008.

[7] M. L. Khan, "Social media engagement: What motivates user participation and consumption on YouTube?," Comput. Human Behav., vol. 66, pp. 236-247, 2017. https://doi.org/10.10 16/j.chb.2016.09.024

[8] S. Alhabash and A. R. McAlister, "Redefining virality in less broad strokes: Predicting viral behavioral intentions from motivations and uses of Facebook and Twitter," New Media Soc., vol. 17, no. 8, pp. 1317-1339, 2014. https://doi.org/10.1177/1461444814523726

[9] G. Feroz Khan and S. Vong, "Virality over YouTube: an empirical analysis," Internet Res., vol. 24, no. 5, pp. 629-647, 2014. https://doi.org/10.1108/intr-05-2013-0085

[10] D. Preece, J., Nonnecke, B Andrews, "The top five reasons for lurking: Improving community experiences for everyone," Comput. Human Behav., vol. 20, no. 2, pp. 201-223, 2004. https://doi.org/10.1016/j.chb.2003.10.015

[11] M. Takahashi, M. Fujimoto, and N. Yamasaki, "The active lurker: Influence of an in-house online community on its outside environment," in Proceedings of the 2003 international ACM SIGGROUP conference on Supporting group work, ACM, 2003, pp. 1-10. https:// doi.org/10.1145/958160.958162

[12] G. Shao, "Understanding the appeal of user-generated media: a uses and gratification perspective," Internet Res., vol. 19, no. 1, pp. 7-25, 2009. https://doi.org/10.1 $\underline{108 / 10662240910927795}$

[13] T. F. Stafford, M. R. Stafford, and L. L. Schkade, "Determining Uses and Gratifications for the Internet," Decis. Sci., vol. 35, no. 2, pp. 259-288, 2004. https://doi.org/10.1111/ j.00117315.2004.02524.x

[14] G. M. Chen, "Tweet this: A uses and gratifications perspective on how active Twitter use gratifies a need to connect with others," Comput. Human Behav., vol. 27, no. 2, pp. 755762, 2011. https://doi.org/10.1016/j.chb.2010.10.023

[15] T. Correa, A. W. Hinsley, and H. G. de Zuniga, "Who interacts on the web?: The intersection of user' personality and social media use," Comput. Hum. Behav., vol. 26, pp. 247-253, 2010. https://doi.org/10.1016/j.chb.2009.09.003

[16] D. L. Swanson, "The uses and misuses of uses and gratifications," Hum. Commun. Research, vol. 3, 1977

[17] S. Butt and J. G. Phillips, "Personality and self reported mobile phone use," Comput. Human Behav., vol. 24, no. 2, pp. 346-360, 2008. https://doi.org/10.1016/j.chb.2007.01.019

[18] R. N. Landers and J. W. Lounsbury, "An investigation of Big Five and narrow personality traits in relation to Internet use," Comput. Hum. Behav., vol. 22, pp. 283-293, 2006. https://doi.org/10.1016/j.chb.2004.06.001

[19] T. Ryan and S. Xenos, "Who uses Facebook? An investigation into the relationship between the Big Five, shyness, narcissism, loneliness, and Facebook usage," Comput. Human Behav., vol. 27, no. 5, pp. 1658-1664, 2011. https://doi.org/10.1016/j.chb.2011.02.004 
[20] G. Seidman, "Self-presentation and belonging on Facebook: How personality influences social media use and motivations," Pers. Individ. Dif., vol. 54, no. 3, pp. 402-407, 2013. https://doi.org/10.1016/j.paid.2012.10.009

[21] T. Tuten and M. Bosnjak, "Understanding differences in Web usage: The role of need for cognition and the five factor model of personality," Soc. Behav. Pers., vol. 29, no. 4, pp. 391-398, 2001. https://doi.org/10.2224/sbp.2001.29.4.391

[22] T. E. Ruggiero, "Uses and gratifications theory in the 21 st century," Mass Commun. Soc., vol. 3, no. 1 , pp. 3-37, 2000.

[23] T. Wang, "The Usage Behaviors, Motivations and Gratifications of Using User-Generated Media: The Case Study of Taiwan's YouTube," no. December, pp. 137-150, 2014. https://doi.org/10.4236/ajc.2014.24015

[24] E. Katz, J. Blumler, and M. Gurevitch, "The Use of Mass Communication," Public Opin. $Q$. , vol. 37, no. 4, pp. 509-523, 1973.

[25] M. Persegani, C., Russo, P., Carucci, C., Nicolini, M., Papeschi, L. L., \& Trimarchi, "Television viewing and personality structure in children," Pers. Individ. Dif., vol. 32, no. 6, pp. 977-990, 2002. https://doi.org/10.1016/s0191-8869(01)00102-7

[26] H. Mendelsohn, "Listening to the radio," in People,society and mass communication, L. A. Dexter and D. M. White, Eds. New York: Free Press, 1964, pp. 239-248.

[27] D. Upadhyaya, "Is Social Media Really Addictive ? Emerging Dimensions of Research," Int. Journal of Research and Analytical Reviews. vol. 5, no. 4, pp. 906-915, 2018.

[28] L. Eunji and L. Jung-ah, "Pictures Speak Louder than Words: Motivations for Using Instagram," vol. 18, no. 9, pp. 552-557, 2015. https://doi.org/10.1089/cyber.2015.0157

[29] D. Baran, S. J., \& Davis, Introduction to mass communication media literacy and culture. New York: The Mc. Grow-Hill Companies, 2004.

[30] E. Katz, J. G. Blumler, and M. Gurevitch, "Uses and gratifications research," Public Opin. $Q$. , vol. 37, no. 4, pp. 509-523, 1974. https://doi.org/10.1086/268109

[31] D. L. Swanson, "Gratification Seeking, Media Exposure, and Audience Interpretations: Some Directions for Research," J. Broadcast. Electron. Media, vol. 31, no. 3, pp. 237-254, 1987. https://doi.org/10.1080/08838158709386662

[32] R. Stoeckl, P. Rohrmeier, and T. Hess, "Motivations To Produce User Generated Content: Differences Between Webloggers And Videobloggers," in BLED, 2007.

[33] S. Finn, "Origins of media exposure: Linking personality traits to TV, radio, print, and film use," Commun. Res., vol. 24, pp. 507-529, 1997. https://doi.org/10.117 7/009365097024005003

[34] K. Yoo and U. Gretzel, "Influence of personality on travel-related consumer-generated media creation," Comput. Human Behav., vol. 27, no. 2, pp. 609-621, 2011. https://doi. org/10.1016/j.chb.2010.05.002

[35] L. Widyanto and M. McMurran, "The psychometric properties of the Internet addiction test," CyberPsychology Behav., vol. 7, pp. 443-450, 2004. https://doi.org/10.1089/cpb.2004.7.443

[36] J. Wu, S. . Wang, and H. H. Tsai, "Falling in love with online games: The uses and gratifications perspective," Comput. Human Behav., vol. 26, no. 6, pp. 1862-1871, 2010. https://doi.org/10.1016/j.chb.2010.07.033

[37] L. A. Pervin and O. P. John, Personality: Theory and research, 7th ed. Oxford: John Wiley and Sons, 1997.

[38] D. R. Shaffer, Social and personality development, 4th ed. Belmont, CA: Wadsworth/Thomson Learning, 2000.

[39] A. B. Woszczynski, P. L. Roth, and A. H. Segars, "Exploring the theoretical foundations of playfulness in computer interactions," Comput. Hum. Behav., vol. 18, no. 4, pp. 369-388, 2002. https://doi.org/10.1016/s0747-5632(01)00058-9 
[40] L. R. Goldberg, "The structure of phenotypic personality traits," Am. Psychol., vol. 48, pp. 26-34, 1993.

[41] U. Gretzel, M. Kang, and W. Lee, "Differences in consumer-generated media adoption and use: A cross-national perspective," J. Hosp. Mark. Manag., vol. 17(1/2), pp. 99-120, 2008. https://doi.org/10.1080/10507050801978240

[42] D. R. Gretzel, U., Lee, Y.-J., Tussyadiah, I., \& Fesenmaier, "Recounting tourism experiences: The role of new media," in International conference on tourist experiences: meanings, motivations, behaviors, 2009.

[43] A. D. Smock, N. B. Ellison, C. Lampe, and D. Y. Wohn, "Facebook as a toolkit: A uses and gratification approach to unbundling feature use," Comput. Human Behav., vol. 27, no. 6, pp. 2322-2329, 2011. https://doi.org/10.1016/j.chb.2011.07.011

[44] A. Whiting and D. Williams, "Why people use social media: a uses and gratifications approach," 2016.

[45] H. Chiang and K. Hsiao, "YouTube stickiness : The needs, personal, and environmental perspective Internet Research Article information:," no. February 2015, 2016. https://doi.org/10.1108/intr-11-2013-0236

[46] S. E. Caplan, "Preference for Online Social Interaction," vol. 30, no. 6, 2003.

[47] Y. Sung, J. A. Lee, E. Kim, and S. M. Choi, "Why we post selfies: Understanding motivations for posting pictures of oneself," Pers. Individ. Dif., vol. 97, pp. 260-265, 2016. https://doi.org/10.1016/j.paid.2016.03.032

[48] J. L. Gibbs, N. B. Ellison, and R. D. Heino, "Self-Presentation in Online Personals," Communic. Res., vol. 33, no. 2, pp. 152-177, 2006.

[49] A. D. I. Kramer and K. Chung, "Dimensions of Self-Expression in Facebook Status Updates," pp. 169-176, 2011.

[50] Z. Papacharissi, "The presentation of self in virtual life: characteristics of personal home pages,” Journal. Mass Commun. Q., vol. 79, no. 3, pp. 643-60, 2002. https://doi.org/10.117 $\underline{7 / 107769900207900307}$

[51] J. Dominick, "Who do you think you are? Personal home pages and self-presentation on the world wide web," Journal. Mass Commun. Q., vol. 76, no. 4, pp. 646-58, 1999. https://doi.org/10.1177/107769909907600403

[52] M. Smith, "E-merging strategies of identity: the rhetorical construction of self in personal web sites,doctoral dissertation," Ohio University, Athens, OH, 1999.

[53] K. Walker, "It is difficult to hide it: the presentation of self on Internet home pages," Qual. Sociol., vol. 23, no. 1, pp. 99-120, 2000.

[54] P. Korgaonkar and L. . Wolin, "A multivariate analysis of web uses," J. Advert. Res., vol. 39, no. 1, pp. 53-68, 1999.

[55] Y. Jung, H. Song, and P. Vorderer, "Why do people post and read personal messages in public? The motivation of using personal blogs and its effects on users' loneliness , belonging , and well-being," Comput. Human Behav., vol. 28, no. 5, pp. 1626-1633, 2012. https://doi.org/10.1016/j.chb.2012.04.001

[56] L. Doster, "Fear of Missing Out: Is Voyeurism the Real Motive Behind Teen Consumption of Social Media ?," vol. 10, pp. 146-147, 2013.

[57] J. M. Metzl, "Voyeur nation? Changing definitions of voyeurism, 1950-2004," Harv. Rev. Psychiatry, vol. 12, no. 2, pp. 127-131, 2004. https://doi.org/10.1080/10673220490447245

[58] C. Calvert, "Voyeur nation: Media, privacy, and peering in modern culture," Crit. Stud. Commun., 2004.

[59] F. Baltar and I. Brunet, "virtual snowball sampling method using Facebook," vol. 22, no. 1, pp. 57-74, 2012. https://doi.org/10.1108/10662241211199960 
[60] A. Kuo, R. J. Lutz, J. L. Hiler, A. Kuo, R. J. Lutz, and J. L. Hiler, "Brave new World of Warcraft : a conceptual framework for active escapism," 2016. https://doi.org/10.1108/jcm$\underline{04-2016-1775}$

[61] P. R. Johnson, "Uses and gratifications of Twitter: An examination of user motives and satisfaction of Twitter use," no. September 2009, 2014.

[62] IPIP, "International personality item pool: A scientific collaboratory for the development of advanced measures of personality traits and other individual differences," 2008. [Online]. Available: http://ipip.ori.org/.

[63] Y. A. Hamburger and E. Ben-Artzi, "The relationship between extraversion and neuroticism and the different uses of the Internet," Comput. Human Behav., vol. 16, pp. 441-449, 2000. https://doi.org/10.1016/s0747-5632(00)00017-0

[64] P. Verna, "User-generated content: More popular than profitable?," eMarketer, 2009. [Online]. Available: http://www.emarketer.com. [Accessed: 20-Dec-2018].

[65] M. Ng, "Factors influencing the consumer adoption of Facebook: A two-country study of youth markets," Comput. Human Behav., vol. 54, pp. 491-500, 2016. https://doi.org/10.10 16/j.chb.2015.08.024

[66] C. H. Hui, "Measurement of individualism-collectivism," J. Res. Pers., vol. 22, no. 1, pp. 17-36, 1988.

[67] N. K. Baym, Y. B. Zhang, and M. Lin, "Social interactions across media," in new media \& society, vol. 6, no. 3, London, Thousand Oaks, CA and New Delhi: SAGE, 2004, pp. 299318. https://doi.org/10.1177/1461444804041438

[68] B. Nonnecke, J. Preece, and K. S. East, "Why lurkers lurk," Am. Conf. Inf. Syst. Bost., vol. 3 , pp. 1-10, 2001.

[69] M. G. Ashton, M. C., Jackson, D. N., Paunonen, S. V., Helmes, E. and Rothstein, "The criterion validity of broad factor scales versus specific facet scales," J. Res. Pers., vol. 29, pp. 432-442, 1995. https://doi.org/10.1006/jrpe.1995.1025

[70] S. V Paunonen, "Sense, nonsense, and the Big Five factors of personality,Invited address," 1993. https://doi.org/10.1037/e569262011-010

[71] A. Schneider, G. Von Krogh, and P. Jäger, "Computers in Human Behavior : What" s coming next ?" Epistemic curiosity and lurking behavior in online communities," Comput. Human Behav., vol. 29, no. 1, pp. 293-303, 2013. https://doi.org/10.1016/j.chb.2012.09.008

[72] B. Baumer, E., Sueyoshi, M., \& Tomlinson, "Exploring the Role of the Reader in the Activity of Blogging," in Shared Authoring. Meeting of Proceedings of the 2008 Conference on Human Factors in Computing Systems, 2008. https://doi.org/10.1145/1357054.1357228

[73] B. K. Kaye, "It's a Blog, Blog, Blog World: Users and Uses of Weblogs," Atl. J. Commun., vol. 13, no. 13-95, 2005. https://doi.org/10.1207/s15456889ajc1302_2

[74] A. Ghose and S. P. Han, "User Content Generation and Usage Behavior on the Mobile Internet: An Empirical Analysis," Ssrn, vol. 57, pp. 1671-1691, 2010. https://doi.org/10.1 287/mnsc. 1110.1350

[75] J. Pybus, "Social Media: Archiving, Engaging and Capturing Youth," 2013.

[76] S. Fricker, M. Galesic, R. Tourangeau, and T. Yan, "An Experimental Comparison of Web and Telephone Surveys," Public Opin. Q., vol. 69, no. 3, pp. 370-392, 2005. https://doi.org/10.1093/poq/nfi027

[77] R. R. Orr, E. S., Sisic, M., Ross, C., Simmering, M. G., Arseneault, J. M., \& Orr, "The influence of shyness on the use of Facebook in an undergraduate sample," CyberPsychology Behav., vol. 12, pp. 337-340, 2009. https://doi.org/10.1089/cpb.2008.0214

[78] B. Omar and K. Subramanian, "Addicted to Facebook: Examining the roles of personality characteristics, gratifications sought and Facebook exposure among youths," Int. J. Media Commun., vol. 1, no. 1, pp. 23-30, 2013. https://doi.org/10.5176/2335-6618 1.1.6 
[79] C. Ross, E. S. Orr, M. Sisic, J. M. Arseneault, M. G. Simmering, and R. R. Orr, "Personality and motivations associated with Facebook use," Comput. Human Behav., vol. 25, no. 2, pp. 578-586, 2009 https://doi.org/10.1016/j.chb.2008.12.024

\section{Authors}

Bahiyah Omar is a senior lecturer at the School of Communication, Universiti Sains Malaysia. Her research interests include social media, online journalism and media effects.

Wang Dequan is a PhD student at the School of Communication, Universiti Sains Malaysia. His research interests include media in China, social media and media effects.

Article submitted 2019-11-19. Resubmitted 2020-01-05. Final acceptance 2019-01-29. Final version published as submitted by the authors. 